\title{
Process optimization for green synthesis of silver nanoparticles by Sclerotinia sclerotiorum MTCC 8785 and evaluation of its antibacterial properties
}

\author{
Juhi Saxena ${ }^{1,2}$, Prashant Kumar Sharma ${ }^{3}$, Madan Mohan Sharma ${ }^{1}$ and Abhijeet Singh ${ }^{*}$
}

\begin{abstract}
Background: Eco-friendly synthesis of nanoparticles is viewed as an alternative to the chemical method and initiated the use of microorganisms for synthesis. The present study has been designed to utilize plant pathogenic fungi Sclerotinia sclerotiorum MTCC 8785 strain for synthesis and optimization of silver nanoparticles (AgNPs) production as well as evaluation of antibacterial properties. The AgNPs were synthesized by reduction of aqueous silver nitrate $\left(\mathrm{AgNO}_{3}\right)$ solution after incubation of 3-5 days at room temperature. The AgNPs were further characterized using UV-visible spectroscopy, Fourier transform infrared spectroscopy (FTIR) and transmission electron microscopy (TEM). Reaction parameters including media, fungal biomass, $\mathrm{AgNO}_{3}$ concentration, $\mathrm{pH}$ and temperature were further optimized for rapid AgNPs production. The antibacterial efficacy of AgNPs was evaluated against Escherichia coli ATCC 25922 and Staphylococcus aureus ATCC 25923 by disc diffusion and growth kinetics assay at the concentration determined by the minimum inhibitory concentration (MIC).

Results: AgNPs synthesis was initially marked by the change in colour from pale white to brown and was confirmed by UV-Vis spectroscopy. Optimization studies showed that potato dextrose broth (PDB) media, $10 \mathrm{~g}$ of biomass, addition of $2 \mathrm{mM} \mathrm{AgNO}_{3}, \mathrm{pH} 11$ and $80^{\circ} \mathrm{C}$ temperature resulted in enhanced AgNPs synthesis through extracellular route. TEM data revealed spherical shape AgNPs with size in the range of $10 \mathrm{~nm}$. Presence of proteins capped to AgNPs was confirmed by FTIR. AgNPs showed antibacterial activity against E. coli and S. aureus at 100 ppm concentration, corresponding MIC value.
\end{abstract}

Conclusion: S. sclerotiorum MTCC 8785 mediated AgNPs was synthesized rapidly under optimized conditions, which showed antibacterial activity.

Keywords: Green synthesis, Sclerotinia sclerotiorum, Silver nanoparticles, Optimization, Antibacterial activity

\section{Background}

Nanotechnology, an emerging field of nanoscience deals with the synthesis and applications of nanoscale materials in diverse interdisciplinary fields like physics, chemistry, biology, medicine and agriculture (Albrecht et al.

\footnotetext{
*Correspondence: abhijeetdhaliwal@gmail.com;

abhijeet.singh@jaipur.manipal.edu

${ }^{1}$ Department of Biosciences, Manipal University Jaipur,

Dehmi Kalan, Near GVK Toll Plaza, Jaipur-Ajmer Express Highway, Jaipur, Rajasthan 303007, India

Full list of author information is available at the end of the article
}

2006). Silver is preferred over other metals in nanoparticle synthesis due to its strong antimicrobial action (Markowska et al. 2013).

Researchers are immensely interested in nanoparticles synthesis by physical or chemical means and nanoparticles synthesized through these routes are designated as engineered nanoparticles (ENPs). Moreover, improper disposal of ENPs lead to their exposure to environment and different ecosystems. In the past few years, interest in extracellular synthesis of nanoparticles mainly by fungi has been increased due to easy synthesis, less 
toxicity, less downstream processing and better optimization control (Pooja et al. 2014). In extracellular synthesis of silver nanoparticles from fungi, firstly biomass is allowed to grow in suitable medium. Fungi respond to different cultural conditions and compositions differently and secrete different metabolites and different kinds of proteins. Fully grown biomass is harvested and separated completely from media components, which is then transferred to deionized water. In water, enzymes or proteins and metabolites have been secreted by fungal biomass through reverse osmosis. In the subsequent stages, removal of biomass from deionized water (cell free filtrate) consists of specific enzymes which catalyze the reduction of aqueous silver ions for synthesis of AgNPs (Birla et al. 2013).

Several fungal species including Fusarium oxysporum (Karbasian et al. 2008), Fusarium semitectum (Basavaraja et al. 2008) Saccharomyces boulardii (Kaler et al. 2013), Alternaria alternata (Gajbhiye et al. 2009), Aspergillus flavus (Jain et al. 2011), Penicillium brevicompactum (Shaligram et al. 2009), Xanthomonas oryzae (Narayanan 2013) have been explored to synthesize AgNPs. Effect of culture medium on the extracellular synthesis of AgNPs using Klebsiella pneumoniae, E. coli and Pseudomonas jessinii have been studied recently (Muller et al. 2016). Authors have concluded that the formation of AgNPs results from the interaction of all medium components. In another study conducted by Morsy Fatthy (2015) have shown that dead bacteria are able to synthesize AgNPs by releasing organics. Both these studies concluded that microorganisms do not per se synthesize AgNPs, hence not biogenic.

Moreover, plant pathogenic fungi which are not harmful to humans can be exploited for nanoparticle synthesis through green chemistry for biomedical applications. In order to increase the yield and the shelf-life (stability) of AgNPs with minimum investment, it is necessary to optimize the cultural conditions and various physical parameters like $\mathrm{pH}$ and temperature.

Bacterial strains have been increasing at an alarming rate and represent a major threat to modern medicine. Emergence of antibiotic resistance is the consequence of a complex interaction of factors involved in the evolution and spread of resistance mechanisms (Holmes et al. 2016). Overuse and inappropriate usage of antibiotics led to the development of antibiotic resistance in clinics. In the recent times, nanomedicine has been evolved with immense potential due to its antimicrobial arsenal to combat pathogenic microbes. AgNPs, a potent bactericidal have been extensively used as bactericidal against Gram positive and Gram negative bacteria.

Presence of protein caps in nanoparticles help in stabilization and binding to cell surface receptor results in increased binding and uptake of drug or genetic material on human cells (Zhang et al. 2013). Hence it is worthwhile to explore the presence of capped protein in AgNPs synthesized from cell free filtrate of $S$. sclerotiorum MTCC 8785, a phytopathogen causing white mold diseases in plants.

The present study deals with the extracellular synthesis of AgNPs using plant pathogenic fungi using S. sclerotiorum MTCC 8785 followed by its characterization and optimization for rapid AgNPs synthesis. Furthermore, antibacterial studies have also been carried out. The study also explores the presence of capping material around the AgNPs.

\section{Methods}

\section{Fungal strain and growth conditions}

The fungal strain S. sclerotiorum MTCC 8785 was obtained from Microbial Type Culture Collection (MTCC), Chandigarh, India. S. sclerotiorum MTCC 8785 was grown on potato dextrose agar (PDA) at $28^{\circ} \mathrm{C}$ for $96 \mathrm{~h}$. The fungal strain was routinely maintained on PDA slants. The test organisms including Gram negative E. coli ATCC 25922 and Gram positive S. aureus ATCC 25923 were procured from Dr. B. Lal clinical laboratory private limited, Jaipur, India.

\section{Extracellular synthesis of AgNPs}

The fungal mycelium grown on PDA was inoculated in production media [potato dextrose broth (PDB)] followed by incubation at $28{ }^{\circ} \mathrm{C}$ for 5 days. Fully grown mycelia were washed with sterile distilled water to remove media components. $5 \mathrm{~g}$ of washed mycelia were added to $10 \mathrm{ml}$ of deionized water and agitated at $28{ }^{\circ} \mathrm{C}$ for $48 \mathrm{~h}$. From the water, mycelia was removed by filtration and the filtrate was collected which is termed as cell free filtrate (CFF). CFF was incubated with $1 \mathrm{mM}$ silver nitrate $\left(\mathrm{AgNO}_{3}\right)$ followed by agitation in a shaker at $120 \mathrm{rpm}$ at $30{ }^{\circ} \mathrm{C}$ in the dark for 3-5 days. A control set without $\mathrm{AgNO}_{3}$ was simultaneously agitated with experimental set (Chowdhury et al. 2014).

\section{Optimization studies for rapid AgNPs synthesis}

Different reaction parameters like media, $\mathrm{AgNO}_{3}$ concentration, fungal biomass, $\mathrm{pH}$ and temperature were optimized to obtain maximum production of AgNPs. Inoculum containing $10^{5}$ spores $/ \mathrm{ml}$ was inoculated in different media like Potato dextrose broth (PDB), Sabouraud's dextrose (SB), Protease production media (PP), Czapek Dox (CZAPEK), Richard medium (RM) and Glucose Yeast Extract Peptone (GYP) was subjected to $1 \mathrm{mM}$ $\mathrm{AgNO}_{3}$ and incubated at $30{ }^{\circ} \mathrm{C}$. Different concentration range of $\mathrm{AgNO}_{3}(0.2-2 \mathrm{mM})$ was added to CFF obtained from fungal biomass grown in optimized media followed by incubation at $30^{\circ} \mathrm{C}$. Furthermore, fungi grown 
in optimized media with different biomass ranging from 0.5 to $10 \mathrm{gm}$ was subjected to optimized concentration of $\mathrm{AgNO}_{3}$ and incubated at $30{ }^{\circ} \mathrm{C}$ to monitor AgNPs synthesis. After this, the optimum concentration of $\mathrm{AgNO}_{3}$ was added to the CFF at different $\mathrm{pH}$ values $(3,5,7,9$ and 11) and incubated at $30{ }^{\circ} \mathrm{C}$. For temperature optimization, CFF containing optimum $\mathrm{AgNO}_{3}$ concentration at optimum $\mathrm{pH}$ was incubated at $4-80{ }^{\circ} \mathrm{C}$. The sample was analyzed with UV-visible absorption spectroscopy to confirm the synthesis of AgNPs (Nayak et al. 2011).

\section{Characterization of silver nanoparticles UV-visible spectroscopy analysis}

$\mathrm{AgNO}_{3}$ treated CFF of $S$. sclerotiorum MTCC 8785 were monitored for reduction of silver ions on UV-visible spectrophotometer 119 (Systronics).

\section{FTIR spectroscopy analysis}

To investigate the presence of capped protein around synthesized AgNPs, Fourier transform infrared (FTIR) spectroscopy was performed. CFF and $\mathrm{AgNO}_{3}$ treated CFF were freeze-dried and FTIR spectrum was recorded on FTIR (Shimazdu, India) in the range of $400-4000 \mathrm{~cm}^{-1}$ at a resolution of $4 \mathrm{~cm}^{-1}$.

\section{TEM analysis}

Morphological characterization of AgNPs was done to assess its shape and size. A drop of solution containing AgNPs was loaded on copper grids in transmission electron microscope (Jeol, USA) and analysis was done for size and shape.

\section{Antibacterial tests}

The antimicrobial activity of AgNPs was evaluated using the minimum inhibitory concentration (MIC) method by broth dilution as per the guidelines of National Committee for Clinical Laboratory Standards (NCCLS). Firstly 1000 ppm of AgNPs solution was prepared by dissolving $1 \mathrm{mg}$ of AgNPs in $1 \mathrm{ml}$ sterile distilled water. Further it was diluted so as to get different concentrations. Test bacterial suspensions (E. coli and $S$. aureus) were diluted in sterile Muller Hinton broth to obtain final inoculums of $10^{6} \mathrm{CFU} / \mathrm{ml}$. The culture flasks containing Muller Hinton broth were treated with various concentrations $(6.25$, 12.5 25, 50, 100, 200 and $400 \mathrm{ppm}$ ) of AgNPs followed by inoculation of $E$. coli and $S$. aureus $\left(10^{6} \mathrm{CFU} / \mathrm{ml}\right)$. The samples were then incubated at $37^{\circ} \mathrm{C}$ at $150 \mathrm{rpm}$ for $24 \mathrm{~h}$. The lowest concentration of AgNPs where no turbidity (visible growth of a microorganism) was observed as MIC. Culture medium containing AgNPs and without test organisms was used as negative control.

Furthermore, growth kinetics of test bacteria in presence of AgNPs was studied as described earlier (Ruparelia et al. 2008). Briefly, $10 \mathrm{ml}$ of nutrient broth was treated with various concentrations (25-125 ppm) of AgNPs, inoculated with overnight grown test bacterial culture $\left(10^{6} \mathrm{CFU} / \mathrm{ml}\right)$ and incubated for $24 \mathrm{~h}$ at $37^{\circ} \mathrm{C}$. Bacterial growth was estimated in spectrophotometer at $600 \mathrm{~nm}$ after $24 \mathrm{~h}$ of incubation. Absorbance of the mixture was recorded at $600-\mathrm{nm}$ wavelength at regular time intervals $(0,4,6,8,10,12$, and 24 h). Sample without AgNPs was used as negative control in this experiment. Ampicillin (10 ppm) and amikacin (30 ppm) were used as positive control against $E$. coli and $S$. aureus respectively.

The antibacterial property of AgNPs synthesized from S. sclerotiorum MTCC 8785 was further evaluated by disc diffusion method against test bacterial strains procured from Dr. B. Lal Clinical laboratory Pvt. Ltd, Jaipur. The bacterial inoculum was prepared by diluting the overnight culture with Mueller-Hinton (MH) broth and inoculated on $\mathrm{MH}$ agar according to Mc. Farland assay in accordance with CLSI guidelines. Paper discs soaked with different concentrations of AgNPs (25, 50, 75 and $100 \mathrm{ppm}$ ) were placed onto $\mathrm{MH}$ agar plates after swabbing with prepared inoculums of $E$. coli and $S$. aureus cultures. The plates were kept overnight at $37{ }^{\circ} \mathrm{C}$ and zone of inhibition was measured (Sarkar et al. 2007). CFF was used as negative control. Ampicillin (10 $\mu \mathrm{g} / \mathrm{disc})$ and amikacin $(30 \mu \mathrm{g} /$ disc $)$ were used as positive control against $E$. coli and $S$. aureus respectively.

\section{Results and discussions}

\section{Extracellular synthesis of AgNPs}

Synthesis of AgNPs from $\mathrm{AgNO}_{3}$ solution using CFF of S. sclerotiorum MTCC 8785 was observed by change in color of the solution (Fig. 1 inset). Color of the solution turned from colorless (Fig. 1 inset left panel) to brown (Fig. 1 inset right panel), which indicated the formation of AgNPs. The appearance of brown color in the solution is indicates the reduction of silver ions to silver. This bioreduction is may be catalyzed by reducing agent secreted by the microorganism in the solution (Ahmad et al. 2003). Furthermore, the extracellular synthesis of AgNPs was confirmed in UV-visible spectroscopy. Absorption spectra showed a strong peak at $430 \mathrm{~nm}$ (Fig. 1), indicated a surface plasmon resonance (SPR), having nanoparticles with sizes less than $100 \mathrm{~nm}$. This could be due to excitation of electrons in the conductive band around the nanoparticles surface as reported by Busi et al. (2014).

\section{Optimization studies for AgNPs production}

Optimization studies were done to support better growth of fungi as well as to enhance better yield of AgNPs. The growth conditions, such as media, $\mathrm{AgNO}_{3}$ concentration, biomass, $\mathrm{pH}$, and temperature directly affecting the productivity were optimized. 


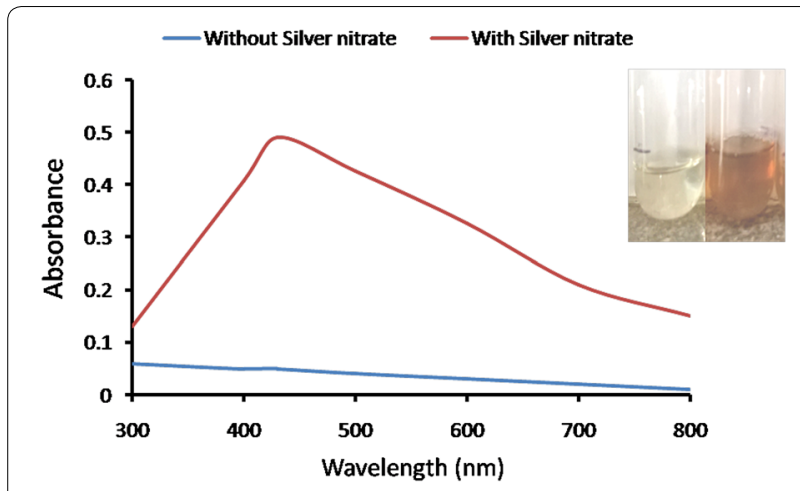

Fig. 1 UV-Vis spectra of AgNPs synthesized using CFF of S. sclerotiorum MTCC 8785. Inset Change in color in CFF after addition of $1 \mathrm{mM}$ $\mathrm{AgNO}_{3}$ at $\mathrm{pH} 7$ followed by incubation at $30^{\circ} \mathrm{C}$

\section{Effect of media}

A range of culture media have been used to grow fungal mycelia for enhanced extracellular synthesis of AgNPs. UV-Vis spectra showed a sharp peak at $430 \mathrm{~nm}$. Fungal biomass grown in PDB has shown enhanced AgNPs synthesis followed by SB, RM, CZAPEK, PP and GYP (Fig. 2). This may be due to presence of ingredients in PDB stimulating better growth of fungi and help in producing augmented level of reducing agent responsible for silver ion reduction (Birla et al. 2013).

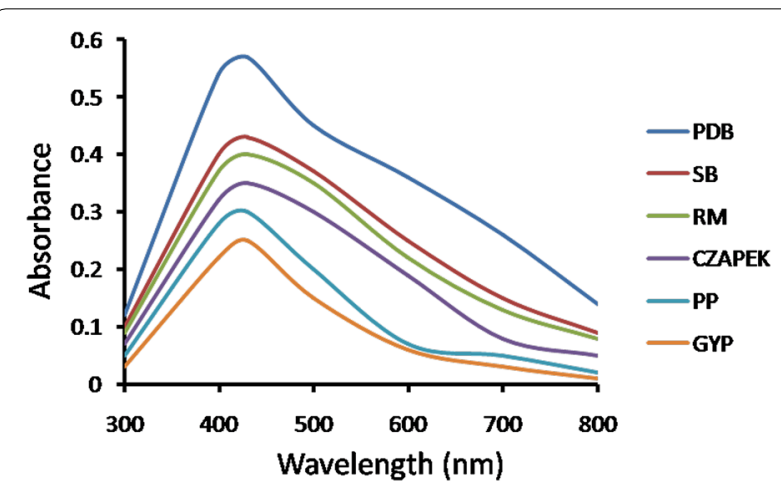

Fig. 2 UV-Vis spectra of AgNPs synthesis using fungi grown in different media followed by addition of $1 \mathrm{mM} \mathrm{AgNO}_{3}$ in CFF of $5 \mathrm{gm}$ biomass and incubated in $\mathrm{pH} 7$ at $30^{\circ} \mathrm{C}$

\section{Effect of $\mathrm{AgNO}_{3}$ concentration}

In order to study the effect of substrate on nanoparticle production, different concentration of $\mathrm{AgNO}_{3}$ solution (0.2-2 mM) was used to synthesize AgNPs using S. sclerotiorum MTCC 8785 . The synthesized AgNPs was monitored by UV-Vis spectral analysis and provided evidence that increase in concentration of $\mathrm{AgNO}_{3}$ up to $2 \mathrm{mM}$ led to complete reduction of $\mathrm{Ag}^{+}$(Fig. 3). Our results correlate with Dattu et al., which shows maximum AgNPs synthesis at $2 \mathrm{mM} \mathrm{AgNO}_{3}$ concentration using Penicillium sp (Singh et al. 2014).

\section{Effect of biomass}

Extracellular synthesis of AgNPs was observed using different amount of fungal biomass ranging from 0.5 to $10 \mathrm{gm}$. UV-visible absorption spectra revealed as the amount of wet biomass increases, synthesis of AgNPs increases which is represented by peak at $430 \mathrm{~nm}$ (Fig. 4). This can be due to directly proportional relationship between amount of biomass and release of reducing agent responsible for AgNPs synthesis (Birla et al. 2013).

\section{Effect of $p H$}

$\mathrm{pH}$ is an essential factor affecting AgNPs production. The effect of varying $\mathrm{pH}$ for maximum AgNPs synthesis, $\mathrm{AgNO}_{3}$ was added in the CFF having different $\mathrm{pH}(3,5$, 7, 9 and 11). The maximum production of AgNPs was attained at $\mathrm{pH} 11$ by change in color when compared with

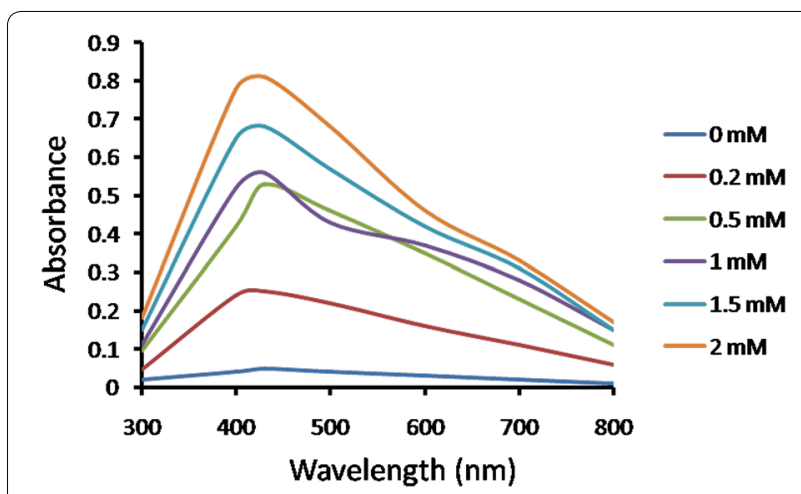

Fig. 3 UV-Vis spectra of AgNPs synthesis using fungi grown in PDB media followed by addition of different concentration of $\mathrm{AgNO}_{3}$ in CFF of $5 \mathrm{gm}$ biomass and incubated in $\mathrm{pH} 7$ at $30^{\circ} \mathrm{C}$ 


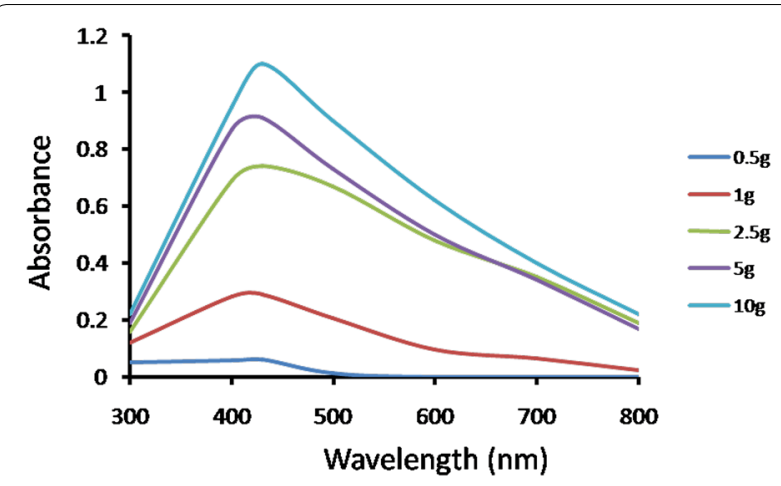

Fig. 4 UV-Vis spectra of AgNPs synthesis using fungi grown in PDB media followed by addition of $2 \mathrm{mM} \mathrm{AgNO}_{3}$ in CFF from different fungal biomass and incubated in $\mathrm{pH} 7$ at $30^{\circ} \mathrm{C}$

other $\mathrm{pH}$ values as demonstrated by UV-visible absorption spectra (Fig. 5). Similar observations have been reported in case of Pseudomonas aeruginosa (Taheri et al. 2011) and Trichoderma viride (Chitra and Annadurai 2013) mediated AgNPs synthesis where high $\mathrm{pH}$ favor the complete reduction of $\mathrm{Ag}^{+}$into AgNPs by providing electrons.

\section{Effect of temperature}

To evaluate the effect of temperature on AgNPs production by S. sclerotiorum MTCC 8785 CFF (pH 11) containing $2 \mathrm{mM} \mathrm{AgNO}_{3}$ was incubated at different temperatures from 20 to $80^{\circ} \mathrm{C}$ with a difference of $20^{\circ} \mathrm{C}$ and monitored for AgNPs synthesis. Maximum synthesis of AgNPs was observed at $80{ }^{\circ} \mathrm{C}$ and remains stable for longer time period indicated stabilized synthesis (Fig. 6). High temperature imparts increased kinetic energy and lead to faster synthesis rate (Birla et al. 2013). After optimization, synthesis was observed within $12 \mathrm{~h}$.

\section{TEM characterization of synthesized AgNPs}

The shape, size and morphology of AgNPs under optimized conditions was studied using TEM. TEM images reported the spherical shape of AgNPs with average particle size ranges from 25 to $30 \mathrm{~nm}$ (Fig. 7a, c). However, when S. sclerotiorum MTCC 8785 was employed under optimized conditions (PDB media, $2 \mathrm{mM} \mathrm{AgNO}_{3}, 10 \mathrm{gm}$ biomass, $\mathrm{pH} 11$ and temperature $80{ }^{\circ} \mathrm{C}$ ), nanoparticles with average size in range of $10-15 \mathrm{~nm}$ were obtained

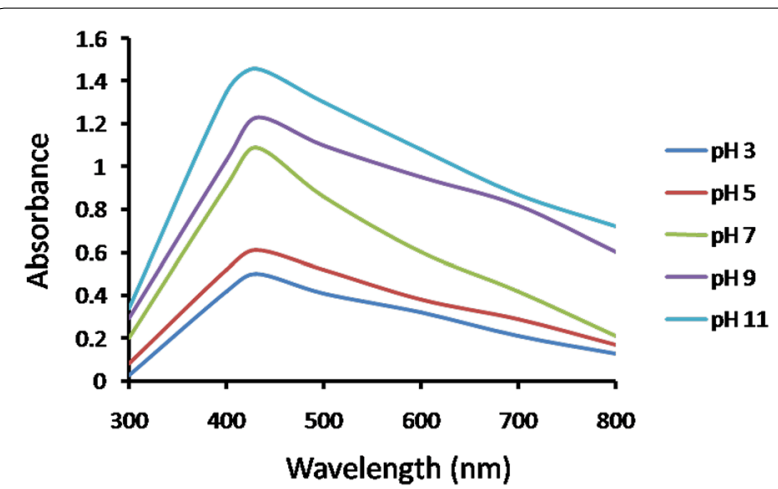

Fig. 5 UV-Vis spectra of AgNPs synthesis using fungi (10 gm biomass) grown in PDB media followed by incubation in different $\mathrm{pH}$ at $30^{\circ} \mathrm{C}$

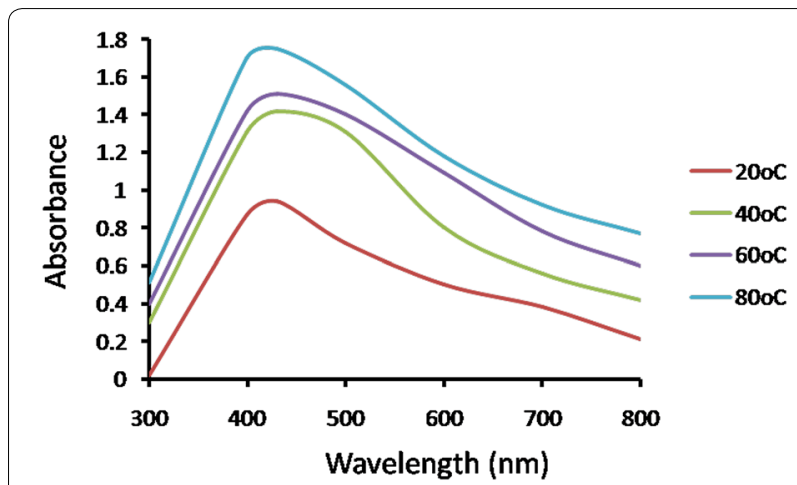

Fig. 6 UV-Vis spectra of AgNPs synthesis using fungi grown in PDB media followed by addition of $2 \mathrm{mM} \mathrm{AgNO}_{3}$ in CFF of $10 \mathrm{gm}$ biomass and incubated in $\mathrm{pH} 11$ at different temperature

(Fig. 7b, d). Selected area electron diffraction pattern (SAED) revealed the crystalline nature of AgNPs synthesised using S. sclerotiorum MTCC 8785 (Fig. 7a inset and c inset). In another study, conducted by Banu et al. (2011) revealed spherical shaped AgNPs, with the size ranging between 3 and $20 \mathrm{~nm}$ by Rhizopus stolonifer.

\section{FTIR characterization of synthesized AgNPs}

FTIR measurement of CFF and synthesized AgNPs was carried out to identify the functional groups present on AgNPs and proteins surrounding AgNPs as stabilization agent. The absorption peaks of cell free filtrate was 

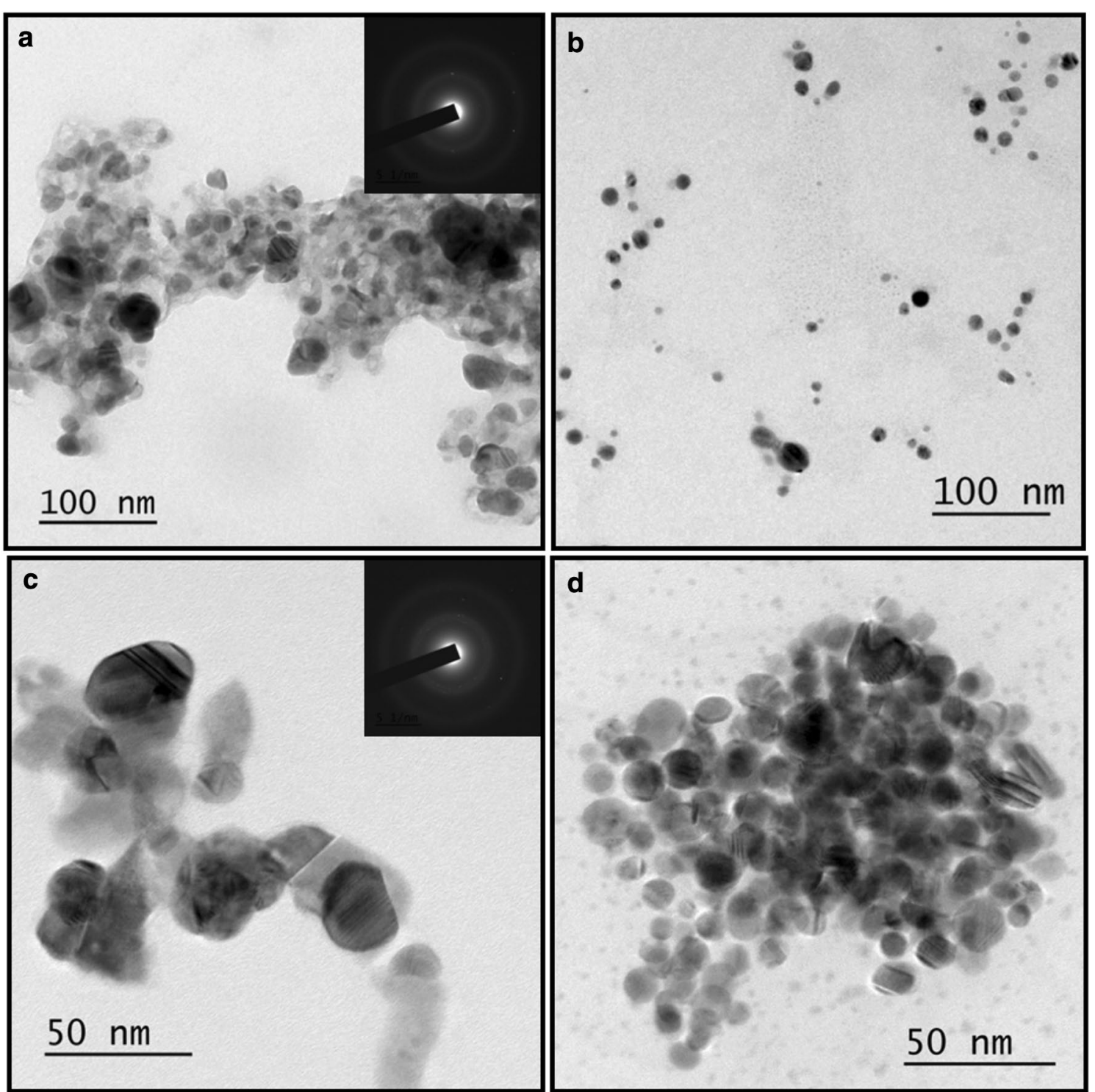

Fig. 7 TEM images of AgNPs synthesized at $30^{\circ} \mathrm{C}$, pH 7 with $1 \mathrm{mM} \mathrm{AgNO}_{3}$ at low (a) and high magnification (c). TEM images for AgNPs synthesized at $80^{\circ} \mathrm{C}, \mathrm{pH} 11$ with $2 \mathrm{mM} \mathrm{AgNO}_{3}$ at low $(\mathbf{b})$ and high magnification $(\mathbf{d})$

located at $715,1028,1228,1326,1444,1530,1637,1719$, 2832, 2884 and $3253 \mathrm{~cm}^{-1}$ (Fig. 8a). However FTIR spectrum of mixture containing CFF and $\mathrm{AgNO}_{3}$ shows peak shifts with intense absorption bands at 511, 800, 824, 1379, 1629, 1762, 2394 and $3223 \mathrm{~cm}^{-1}$ (Fig. 8b). Presence of peak at 3223 and $3253 \mathrm{~cm}^{-1}$ may be assigned to
$\mathrm{N}-\mathrm{H}$ stretch which corresponds to primary and secondary amines. Presence of band at 23,884 and $2390 \mathrm{~cm}^{-1}$ correspond to $-\mathrm{C} \equiv \mathrm{N}$ stretching vibrations. The peaks seen at 1762,1719 and $1629 \mathrm{~cm}^{-1}$ assigned to $\mathrm{C}=\mathrm{O}$ and $\mathrm{N}-\mathrm{H}$ bend (primary amine) of peptide linkage respectively. Difference in peaks in CFF and mixture containing 

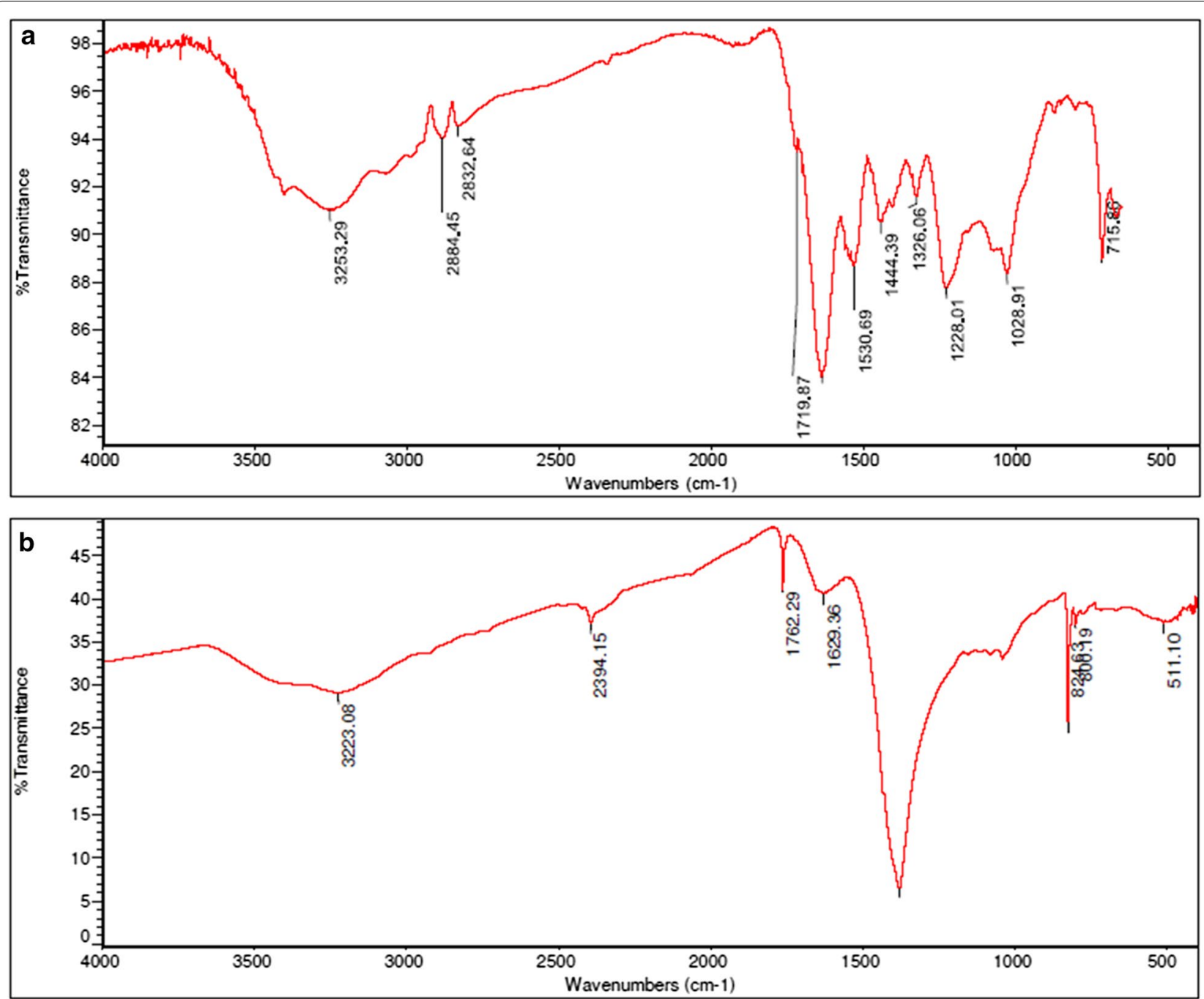

Fig. 8 FTIR spectra of $\mathbf{a}$ cell free filtrate and $\mathbf{b}$ synthesized AgNPs

CFF and $\mathrm{AgNO}_{3}$ suggested that reaction between biomolecules present in CFF with $\mathrm{AgNO}_{3}$ has occurred and new product in the form of AgNPs have been formed. FTIR study indicates that probably the carboxyl $(-\mathrm{C}=\mathrm{O})$ and amine $(\mathrm{N}-\mathrm{H})$ groups in CFF are mainly involved in the reduction of $\mathrm{Ag}^{+}$ions to AgNPs. Furthermore, FTIR analysis also confirmed the presence of proteins around the AgNPs acting as reducing as well as stabilizing agent during synthesis of AgNPs (Daima et al. 2013; Venkatesan et al. 2014) (Additional file 1: Fig. S1).

\section{Antibacterial efficacy}

Table 1 shows MIC value of AgNPs against E. coli and $S$. aureus. MIC against both the bacterial strains was $100 \mathrm{ppm}$ as demonstrated by broth dilution method. Furthermore, the antibacterial activity of AgNPs synthesized using CFF of S. sclerotiorum MTCC 8785 was evaluated
Table 1 Minimum Inhibitory Concentration (MIC) of AgNPs against $E$. coli and S. aureus

\begin{tabular}{lll}
\hline S. no. & Bacterial strains & MIC of AgNPs (ppm) \\
\hline 1. & E. coli & 100 \\
2. & S. aureus & 100 \\
\hline
\end{tabular}

against $E$. coli and $S$. aureus by bacterial growth kinetics study. The results depicted in Fig. 9 demonstrated the inhibition in the growth kinetics of test bacteria as compared to the cultures grown in absence of AgNPs. Reduction in the growth profile of E. coli (Fig. 9a) and S. aureus (Fig. 9b) was observed at $100 \mathrm{ppm}$ of AgNPs as compared to the control sample. No growth was observed at 125 ppm of AgNPs. Furthermore, antibacterial activity 

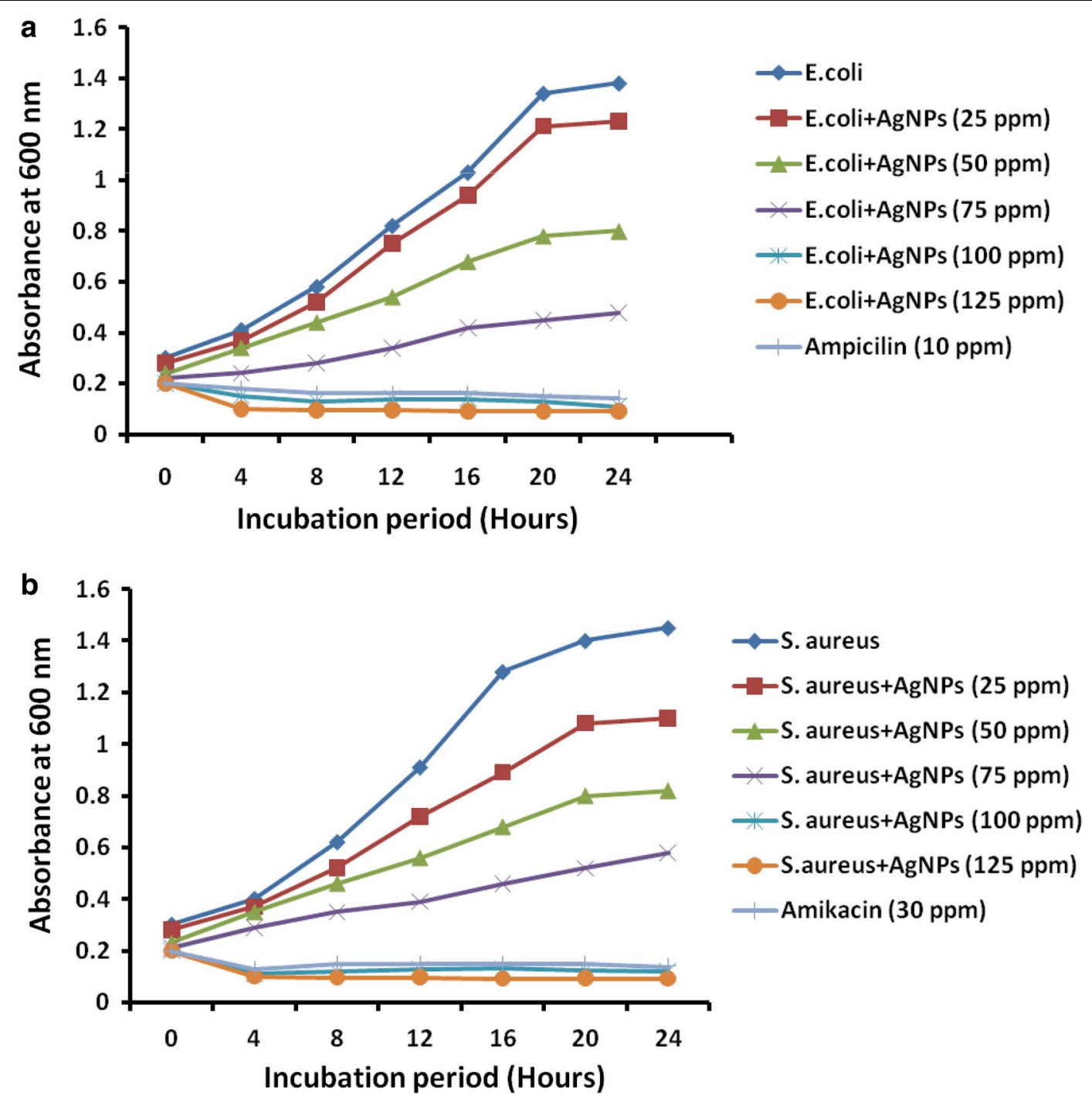

Fig. 9 Growth profiles of $\mathbf{a}$ E. coli and $\mathbf{b}$ S. aureus in the presence of varying amounts of AgNPs (25-125 ppm)

was assessed by disc diffusion assay and zone of inhibition was depicted in Fig. 10. AgNPs showed antibacterial activity and inhibitory zone of $20 \mathrm{~mm}$ was recorded against E. coli at $100 \mathrm{ppm}$ of AgNPs (Fig. 10Ae). For S. c zone of inhibition at $100 \mathrm{ppm}$ (Fig. 10Be) (Table 1). It may be due to perforation and lysis of AgNPs to the bacterial cell wall followed by generation of free radicals (Prabhu and Poulose 2012) and degradation of DNA (Duran et al. 2015). Zone of inhibition of E. coli and S. aureus againt $\mathrm{AgNO}_{3}$ and increasing concentration of AgNPs has been shown in Table 2. $\mathrm{AgNO}_{3}$ shown less zone of inhibition as compared to AgNPs at similar concentration suggested antibacterial activity is due to AgNPs. This can be due to reduction of $\mathrm{AgNO}_{3}$ into AgNPs which resulted in increased surface area that lead to better surface contact with bacteria and hence better bactericidal in nature (Prabhu and Poulose 2012). Ampicillin (10 $\mu \mathrm{g} /$ disc) and amikacin $(30 \mu \mathrm{g} / \mathrm{disc})$ were used as positive control against E. coli (Fig. 10Af) and S. aureus (Fig. 10Bf) respectively. Cell free filtrate was used as negative control 

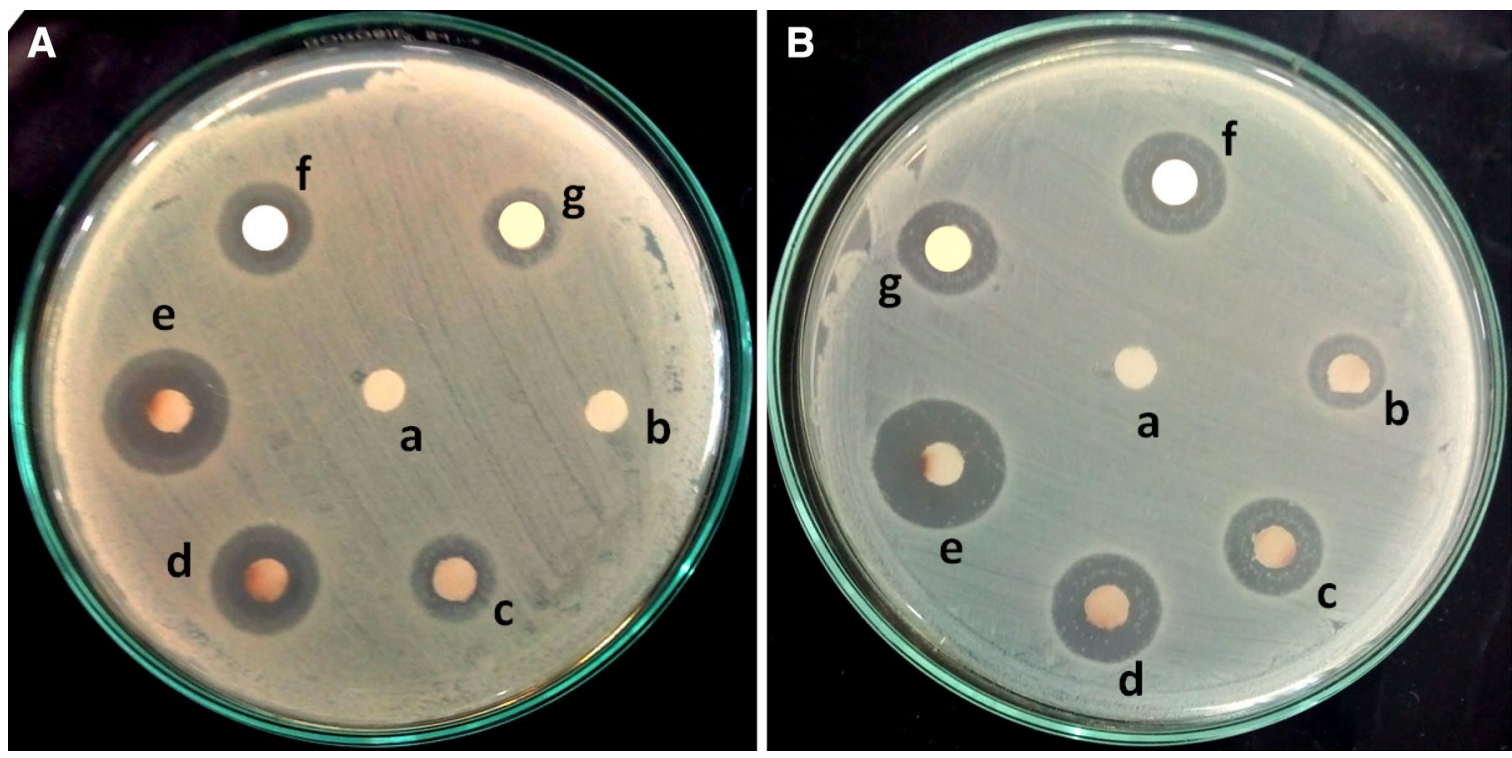

Fig. 10 Zone of inhibition at different concentration of AgNPs against $\mathbf{A}$ E. coli and $\mathbf{B}$ S. aureus. a Cell free filtrate, $b 25$ ppm, c 50 ppm, $d 75$ ppm and e $100 \mathrm{ppm}$ of AgNPs, fampicillin (10 $\mathrm{gg} /$ disc) for E. coli and amikacin $\left(30 \mu \mathrm{g} /\right.$ disc) for S. aureus, $g 100 \mathrm{ppm}$ of $\mathrm{AgNO}_{3}$

Table 2 Zone of inhibition of $\mathrm{AgNPs}_{1} \mathrm{AgNO}_{3}$ and standard antibiotics against $\mathrm{E}$. coli and S. aureus

\begin{tabular}{|c|c|c|c|c|c|c|c|c|}
\hline \multirow[t]{3}{*}{ S. no. } & \multirow[t]{3}{*}{ Bacterial strains } & \multicolumn{7}{|c|}{ Zone of inhibition $(\mathrm{mm}) \pm$ SEM } \\
\hline & & \multicolumn{4}{|l|}{ AgNPs } & \multirow{2}{*}{$\begin{array}{l}\mathrm{AgNO}_{3} \\
100 \mathrm{ppm}\end{array}$} & \multirow{2}{*}{$\begin{array}{l}\text { Ampicillin } \\
(10 \mu \mathrm{g} / \text { disc })\end{array}$} & \multirow{2}{*}{$\begin{array}{l}\text { Amikacin } \\
(30 \mu \mathrm{g} / \mathrm{disc})\end{array}$} \\
\hline & & $25 \mathrm{ppm}$ & $50 \mathrm{ppm}$ & 75 ppm & 100 ppm & & & \\
\hline 1. & E. coli & 0 & $7 \pm 0.4$ & $15 \pm 1.2$ & $20 \pm 1.3$ & $11 \pm 1.1$ & $15 \pm 0.9$ & - \\
\hline 2. & S. aureus & $5 \pm 0.3$ & $9 \pm 0.6$ & $14 \pm 1.6$ & $19 \pm 1.2$ & $12 \pm 0.8$ & - & $17 \pm 1.3$ \\
\hline
\end{tabular}

(Fig. 10Aa, Ba). AgNPs showed maximum antibacterial activity as demonstrated by growth kinetics and disc diffusion assay at $100 \mathrm{ppm}$ which is in agreement with MIC value.

\section{Conclusion}

In conclusion, AgNPs can be synthesized using CFF of S. sclerotiorum MTCC 8785. Optimization of physical and cultural conditions revealed enhanced AgNPs synthesis in PDB grown fungi with 10 gm of biomass treated with $2 \mathrm{mM} \mathrm{AgNO}_{3} \mathrm{pH} 11$ and incubated at $80{ }^{\circ} \mathrm{C}$. The green synthesized AgNPs were of $10 \mathrm{~nm}$ size and having protein as stabilizing agent under optimized conditions. AgNPs showed antibacterial activity against E. coli and S. aureus. Hence, green synthesis of AgNPs using S. sclerotiorum MTCC 8785 with potent antibacterial activities can be exploited on a large scale for medical application.

\section{Additional file}

Additional file 1: Fig. S1. Comparison of UV-Vis spectra of AgNPs before (A) and after purification (B).

\section{Authors' contributions}

JS, PKS, MMS and AS participated in the design of the study, conduction of experiments and took part in the evaluation of the results. All authors read and approved the final manuscript.

\section{Author details}

${ }^{1}$ Department of Biosciences, Manipal University Jaipur, Dehmi Kalan, Near GVK Toll Plaza, Jaipur-Ajmer Express Highway, Jaipur, Rajasthan 303007, India. ${ }^{2}$ Dr. B. Lal Institute of Biotechnology, Malviya Industrial Area Jaipur, Jaipur, India. ${ }^{3}$ Dr. M.P.S. College, Agra, India.

\section{Acknowledgements}

We are thankful to Manipal University Jaipur and Dr. B. Lal Institute of Biotechnology for providing necessary facilities and valuable support throughout the work. 


\section{Competing interests}

The authors declare that they have no competing interests.

Received: 2 March 2016 Accepted: 10 June 2016

Published online: 24 June 2016

\section{References}

Ahmad A, Mukherjee P, Senapati S, Mandal D, Khan MI, Kumar R, Sastry M (2003) Extracellular biosynthesis of silver nanoparticles using the fungus Fusarium oxysporum. Colloids Surf B Biointerfaces 28:313-318

Albrecht M, Evans C, Raston C (2006) Green chemistry and the health implications of nanoparticles. Green Chem 8:417

Banu A, Rathod V, Ranganath E (2011) Silver nanoparticle production by Rhizopus stolonifer and its antibacterial activity against extended spectrum $\beta$-lactamase producing (ESBL) strains of Enterobacteriaceae. Mater Res Bull 46:1417-1423

Basavaraja S, Balaji S, Lagashetty A, Rajasab A, Venkataraman A (2008) Extracellular biosynthesis of silver nanoparticles using the fungus Fusarium semitectum. Mater Res Bull 43:1164-1170

Birla S, Gaikwad S, Gade A, Rai M (2013) Rapid synthesis of silver nanoparticles from fusarium oxysporum by optimizing physicocultural conditions. Sci World J 2013:1-12

Busi S, Rajkumari J, Karuganti S, Ranjan B (2014) Green rapid biogenic synthesis of bioactive silver nanoparticles (AgNPs) using Pseudomonas aeruginosa. IET Nanobiotechnol 8:267-274

Chitra K, Annadurai G (2013) Bioengineered silver nanobowls using Trichoderma viride and its antibacterial activity against Gram-positive and Gram-negative bacteria. J Nanostruct Chem 3:9

Chowdhury S, Basu A, Kundu S (2014) Green synthesis of protein capped silver nanoparticles from phytopathogenic fungus Macrophomina phaseolina (Tassi) Goid with antimicrobial properties against multidrug-resistant bacteria. Nanoscale Res Lett 9:365

Daima H, Selvakannan P, Shukla R, Bhargava S, Bansal V (2013) Fine-tuning the antimicrobial profile of biocompatible gold nanoparticles by sequential surface functionalization using polyoxometalates and lysine. PLoS One 8:e79676

Duran N, Duran M, de Jesus MB, Seabra AB, Favaro WJ, Nakazato G (2015) Silver nanoparticles: a new view on mechanistic aspects on antimicrobial activity. Nanomed Nanotechnol Biol Med 12:789-799

Gajbhiye M, Kesharwani J, Ingle A, Gade A, Rai M (2009) Fungus-mediated synthesis of silver nanoparticles and their activity against pathogenic fungi in combination with fluconazole. Nanomed Nanotechnol Biol Med 5:382-386

Holmes AH, Moore LS, Sundsfiord A, Steinbakk M, Regmi S, Karkey A, Guerin PJ Piddock $L$ (2016) Understanding the mechanisms and drivers of antimicrobial resistance. Lancet 387:176-187

Jain N, Bhargava A, Majumdar S, Tarafdar J, Panwar J (2011) Extracellular biosynthesis and characterization of silver nanoparticles using Aspergillus flavus NJP08: a mechanism perspective. Nanoscale 3:635-641
Kaler A, Jain S, Banerjee U (2013) Green and rapid synthesis of anticancerous silver nanoparticles by Saccharomyces boulardii and insight into mechanism of nanoparticle synthesis. BioMed Res Int 2013:1-8

Karbasian M, Atyabi SM, Siadat SD, Momen SB, Norouzian D (2008) Optimizing nano-silver formation by Fusarium oxysporum ptcc 5115 employing response surface methodology. Am J Agric Biol Sci 3:433-437

Markowska K, Grudniak AM, Wolska KI (2013) Silver nanoparticles as an alternative strategy against bacterial biofilms. Acta Biochim Pol 60:523-530

Morsy Fatthy M (2015) Toward revealing the controversy of bacterial biosynthesis versus bactericidal properties of silver nanoparticles (AgNPs): bacteria and other microorganisms do not per se viably synthesize AgNPs. Arch Microbiol 197:645-655

Muller A, Behsnilian D, Walz E, Graf V, Hogekamp L, Greiner R (2016) Effect of culture medium on the extracellular synthesis of silver nanoparticles using Klebsiella pneumoniae, Escherichia coli and Pseudomonas jessinii. Biocatal Agric Biotechnol 6:107-115

Narayanan K (2013) Biosynthesis of silver nanoparticles by phytopathogen Xanthomonas oryzae pv. oryzae strain BXO8. J Microbiol Biotechnol 23:1287-1292

Nayak R, Pradhan N, Behera D, Pradhan K, Mishra S, Sukla L, Mishra B (2011) Green synthesis of silver nanoparticle by Penicillium purpurogenum NPMF: the process and optimization. J Nanopart Res 13:3129-3137

Pooja B, Joginder S, Suresh K (2014) Biogenesis of nanoparticles: a review. Afr J Biotechnol 13:2778-2785

Prabhu S, Poulose E (2012) Silver nanoparticles: mechanism of antimicrobial action, synthesis, medical applications, and toxicity effects. Int Nano Lett $2 \cdot 32$

Ruparelia Jayesh J, Chatterjee Arup K, Duttagupta Siddhartha P, Mukherji S (2008) Strain specificity in antimicrobial activity of silver and copper nanoparticles. Acta Biomater 4:707-716

Sarkar S, Jana A, Samanta S, Mostafa G (2007) Facile synthesis of silver nano particles with highly efficient anti-microbial property. Polyhedron 26:4419-4426

Shaligram N, Bule M, Bhambure R, Singhal R, Singh S, Szakacs G, Pandey A (2009) Biosynthesis of silver nanoparticles using aqueous extract from the compactin producing fungal strain. Process Biochem 44:939-943

Singh D, Rathod V, Ninganagouda S, Hiremath J, Singh A, Mathew J (2014) Optimization and characterization of silver nanoparticle by endophytic fungi Penicillium sp. isolated from Curcuma longa (turmeric) and application studies against MDR E. coli and S. aureus. Bioinorg Chem Appl 2014:1-8

Taheri Otaqsara S (2011) Biosynthesis of quasi-spherical Ag nanoparticle by Pseudomonas aeruginosa as a bioreducing agent. Eur Phys J Appl Phys 56:30402

Venkatesan B, Subramanian V, Tumala A, Vellaichamy E (2014) Rapid synthesis of biocompatible silver nanoparticles using aqueous extract of Rosa damascena petals and evaluation of their anticancer activity. Asian Pac J Trop Med 7:S294-S300

Zhang Y, Cheng X, Zhang Y, Xue X, Fu Y (2013) Biosynthesis of silver nanoparticles at room temperature using aqueous aloe leaf extract and antibacterial properties. Colloids Surf A 423:63-68

\section{Submit your manuscript to a SpringerOpen ${ }^{\circ}$ journal and benefit from:}

- Convenient online submission

- Rigorous peer review

- Immediate publication on acceptance

- Open access: articles freely available online

High visibility within the field

- Retaining the copyright to your article

Submit your next manuscript at springeropen.com 